\title{
Cardiovascular risk profile in Olympic athletes: an unexpected and underestimated risk scenario
}

\author{
Flavio D'Ascenzi, ${ }^{1}$ Stefano Caselli, ${ }^{2}$ Federico Alvino, ${ }^{1}$ Barbara Digiacinto, ${ }^{2}$ \\ Erika Lemme, ${ }^{2}$ Massimo Piepolii, ${ }^{3}$ Antonio Pelliccia ${ }^{2}$
}

\begin{abstract}
- Additional material is published online only. To view, please visit the journal online (http://dx.doi.org/10.1136/ bjsports-2018-099530).

${ }^{1}$ Department of Medical Biotechnologies, Division of Cardiology, University of Siena, Siena, Italy

${ }^{2}$ Institute of Sports Medicine and Science, Rome, Italy

${ }^{3}$ Heart Failure Unit, Cardiology, G da Saliceto Hospital, Piacenza, Italy
\end{abstract}

\section{Correspondence to}

Dr Flavio D'Ascenzi, Department of Medical Biotechnologies, Division of Cardiology, University of Siena, Siena 53100, Italy;

flavio.dascenzi@unisi.it

Accepted 28 August 2018 Published Online First 14 September 2018
ABSTRACT

Background Prevalence of cardiovascular (CV) risk factors has been poorly explored in subjects regularly engaged in high-intensity exercise programmes. Our aim was, therefore, to assess the prevalence and distribution of $\mathrm{CV}$ risk factors in a large population of competitive athletes, to derive the characteristics of athlete's lifestyle associated with the best CV profile.

Methods 1058 Olympic athletes (656 males, 402 females), consecutively evaluated in the period 20142016, represent the study population. Prevalence and distribution of CV risk factors was assessed, in relation to age, body size and sport.

Findings Dyslipidemia was the most common risk (32\%), followed by increased waist circumference $(25 \%)$, positive family history $(18 \%)$, smoking habit $(8 \%)$, hypertension (3.8\%) and hyperglycaemia $(0.3 \%)$. Large subset of athletes $(418,40 \%)$ had none or $1(414$, $39 \%)$ risk factor, while only a few $(39,3.7 \%)$ had $3 / 4$ CV risk factors. The group without risks largely comprised endurance athletes (34\%). Ageing was associated with higher total and low-density lipoprotein cholesterol, triglycerides $(p<0.001)$ and glycaemia $(p=0.002)$ and lower high-density lipoprotein cholesterol. On multivariate logistic regression analysis, age, BMI and body fat were identified as independent predictors of increased CV risk.

Interpretation Dyslipidemia and increased waist circumference are common in elite athletes $(32 \%$ and $25 \%$, respectively). A large proportion ( $40 \%$ ) of athletes, mostly endurance, are totally free from risk factors. Only a minority (3\%) presents a high CV risk, largely expression of lifestyle and related to modifiable CV risk factors.

\section{INTRODUCTION}

Cardiovascular (CV) diseases are the leading cause of morbidity and mortality worldwide, prompting the scientific societies to actively promote preventive appropriate strategies to reduce the incidence and progression of this pandemic. ${ }^{1}$ Regular physical exercise is accepted to play an important role in the prevention of $\mathrm{CV}$ diseases, being associated with lower incidence and severity of CV diseases. ${ }^{1}$ The beneficial consequences of exercise programmes are believed to be (partly) mediated by tempering the prevalence and severity of CV risk factors.

Despite several observational studies have reported the effect of regular physical exercise on populations at moderate-to-high $\mathrm{CV}$ risk profile, more scantly and less consistent information are available on CV risks in subjects regularly engaged in high-intensity physical activity, such as competitive athletes.

\section{What are the findings?}

- Dyslipidemia and increased waist circumference are common in elite athletes (32\% and 25\%, respectively).

- A large proportion (40\%) of athletes, mostly endurance, are totally free from risk factors.

- Only a minority (3\%) presents a high cardiovascular (CV) risk, related to modifiable CV risk factors.

How might it impact on clinical practice in the future?

Sport participation does not guarantee, per se, to eliminate being overweight and does not eliminate the trend towards an increase in cholesterol and glucose. therefore, a healthy lifestyle including regular exercise and an adequate diet and stop smoking should be encouraged.

- Body mass index and body fat are independent predictors of increased CV risk also in top-level athletes and should be monitored for their impact on athletic performance and on CV risk.

- Waist circumference and body composition should be used to define overweight in order to avoid misclassifications in top-level athletes.

Athletes are assumed to have a low-risk profile, due to the usual young adult age and the effect of regular exercise programmes, and are instinctively believed to represent the model of a healthy lifestyle; however, there are no large registries supporting this assumption and the current algorithms are considered inadequate to assess the $\mathrm{CV}$ risk in these subjects. ${ }^{23}$

Moreover, this view has been challenged by observations describing an unexpected large prevalence of $\mathrm{CV}$ risk factors in selected cohorts of athletes such football players that were active professional, retire middle-aged and also young college athletes. ${ }^{4-11}$

Therefore, we planned the present study to assess the prevalence and distribution of $\mathrm{CV}$ risk factors in a large population of male and female Olympic athletes, considered to represent the model of physically active and healthy lifestyle. We sought to assess the extent and distribution of CV risk factors and derive the athletic characteristics associated with the best advisable CV profile. 


\section{METHODS}

\section{Setting}

The Institute of Sport Medicine and Science in Rome is the division of the Italian Olympic Committee responsible for medical evaluation of the elite athletes selected for participation to the Olympic Games and/or World Championships. The medical programme implemented for Olympic athletes comprises history, physical examination with anthropometric parameters including body composition, blood testing and cardiac assessment with 12-lead and exercise electrocardiography and echocardiography. ${ }^{12}$

\section{Study population}

From January 2014 to June 2016, 1190 elite athletes were evaluated as members of the Italian team selected as potential competitors in the Olympics. Athletes were examined during period of intense exercise conditioning, after a long-term career (3-15 years, average 6) of regular exercise training and competition at national/international level. After the rationale and protocol of the study were explained, the participants gave their written informed consent.

For the purpose of the present investigation, and due to limited sample size, athletes $<15$ or $>45$ years of age were excluded. Accordingly, the final study population consisted of 1058 consecutive athletes (656 males, 402 females), mostly Caucasians (98\%), with mean age $24 \pm 6$ (1 SD) years.

Athletes participated in a broad spectrum of 28 sport disciplines, arbitrarily classified into four groups ${ }^{13}{ }^{14}$ : 1) skill (ie, primarily technical disciplines), $\mathrm{n}=227$ (21\%), including archery, equestrian, golf, shooting; 2) power (ie, primarily strength disciplines), $\mathrm{n}=193$ (18\%), including weightlifting, Greco Roman wrestling, judo, javelin, shot-putting; 3) mixed disciplines (ie, activities with alternate isometric and isotonic components, $\mathrm{n}=345$ (33\%), including soccer, fencing, volleyball, basketball, tennis and 4) endurance disciplines (ie, primarily dynamic components), $\mathrm{n}=293$ (28\%), including cycling, rowing, triathlon, long-distance running.

\section{Clinical evaluation}

All athletes included in the present analysis were asymptomatic. None was taking regularly drugs under medical prescription administered for dyslipidemia while four people took antihypertensive drugs and one was under insulin treatment for type 1 diabetes mellitus. All athletes denied use of performance-enhancing or illicit drugs and have undergone serial WADA and National Anti-doping Agency mandatory controls for checking possible abuse of banned drugs. ${ }^{15}$ The athletes were advised to withdraw training or competition within the 12 hours prior our medical evaluation. Blood pressure was measured in the sitting position before exercise testing, as recommended. ${ }^{1}$ Body height and weight were obtained in each subject and body mass index (BMI) was calculated as weight in kilograms divided by the square of the height in metres. Body surface area (BSA) was derived by the Mosteller formula. ${ }^{16}$ Body composition and fat percentage were measured using Bioelectric Impedance Analysis (BIA 101 Quantum, Akern, Italy) using constant sinusoidal current, at an intensity of $50 \mathrm{kHz}$ and $400 \mu \mathrm{A}$. Standard 12-lead ECG was performed in supine position and interpretation made according to the recent international criteria for ECG interpretation in athletes. ${ }^{17}$ All participants underwent maximal exercise testing on bicycle ergometer (Cubestress XR400; Cardioline SpA, Milan, Italy) as previously reported. ${ }^{18}$

\section{Echocardiographic examination}

Two-dimensional echocardiography was performed with Philips EPIQ 7 (Philips Medical System, Andover, Massachusetts, USA). Cardiac images were obtained in multiple cross-sectional planes using standard transducer positions. Images were obtained and interpreted by two expert cardiologists. Measurements of end-diastolic and end-systolic left ventricular (LV) cavity dimensions, ventricular septum and posterior free wall thicknesses were obtained according to the current recommendations. ${ }^{19} 20$ LV mass was calculated by the Devereux formula. ${ }^{21} \mathrm{LV}$ ejection fraction was calculated with biplane method of disks summation (modified Simpson's rule). ${ }^{21} \mathrm{LV}$ diastolic function was evaluated both by pulsed-wave Doppler (PW) and tissue Doppler imaging, as recommended. ${ }^{22}$

\section{Risk factors definition}

Family history: fatal or non-fatal CV events or/and established diagnosis of $\mathrm{CV}$ disease in first-degree male relatives before 55 years, or female relatives before 65 years. ${ }^{1}$

Cigarette smoking: defined as regularly smokers of at least one cigarette per day.

Overweight: in order to avoid misclassifying subjects with increased muscular mass and high BMI as overweight, our definition of overweight was a waist circumference $>94 \mathrm{~cm}$ for men or $>80 \mathrm{~cm}$ for women. ${ }^{1}$

Hypertension: diagnosis of hypertension was considered when systolic blood pressure was $\geq 140 \mathrm{~mm} \mathrm{Hg}$ and/or diastolic was $\geq 90 \mathrm{~mm} \mathrm{Hg}$ or subjects were in treatment with antihypertensive drugs. ${ }^{1}$

Diabetes: diagnosis was made if fasting glucose was $\geq 126 \mathrm{mg} /$ $\mathrm{dL}$ or current treatment with insulin or antidiabetic drugs. ${ }^{23}$

Dyslipidemia: was defined for a low-density lipoprotein (LDL) $\geq 115 \mathrm{mg} / \mathrm{dL}^{24}$

Age: for the purpose of the study, athletes were arbitrarily classified as adolescent (15-20 years), young (21-29 years) and older adults (30-45 years).

\section{Statistical analysis}

Continuous data were expressed as mean \pm SD and categorical data as number of observations and frequencies. Differences between groups were evaluated with unpaired T-test; difference between proportions was calculated by $\mathrm{X}^{2}$ test. Statistical significance was assumed if the null hypothesis could be rejected at $p<0.05$. Population was divided according either to type of sport participated, age or number of risk factors. Differences among age groups were assessed with analysis of variance and post hoc Bonferroni correction.

Binary logistic regression analysis was used to identify the variables associated with the highest $\mathrm{CV}$ risk profile (ie, presence of three to four risk factors). Factors with a univariate value of $\mathrm{p}<0.05$ were included in a stepwise multivariate logistic regression analysis. Categorical variables comprised gender and type of sport. Specifically, the impact of type of sport was assessed using $\mathrm{N}-1$ dummy variables, with skill disciplines chosen as the reference value. Statistical analysis was performed with SPSS software (V.22; SPSS, Chicago, Illinois, USA).

\section{RESULTS}

\section{Demographic and clinical characteristics}

The demographic, clinical and echocardiographic characteristics of the overall study population according to age are reported in table 1 . 
Table 1 Demographic, clinical and echocardiographic characteristics of the study population according to age

\begin{tabular}{|c|c|c|c|c|}
\hline Parameter & $\begin{array}{l}\text { Adolescent } \\
\text { athletes (a) } \\
\mathrm{n}=292\end{array}$ & $\begin{array}{l}\text { Young adult } \\
\text { athletes (b) } \\
\mathrm{n}=569\end{array}$ & $\begin{array}{l}\text { Older adult } \\
\text { athletes (c) } \\
\mathrm{n}=197\end{array}$ & $P$ values \\
\hline Height, cm & $177 \pm 12$ & $179 \pm 11$ & $180 \pm 11$ & 0.019 \\
\hline Weight, kg & $69 \pm 13^{*} \dagger$ & $74 \pm 15 \ddagger$ & $77 \pm 15 \ddagger$ & $<0.001$ \\
\hline $\mathrm{BSA}, \mathrm{m}^{2}$ & $1.84 \pm 0.22 * \dagger$ & $1.92 \pm 0.24 \ddagger$ & $1,95 \pm 0,24 \ddagger$ & $<0.001$ \\
\hline $\mathrm{BMI}, \mathrm{kg} / \mathrm{m}^{2}$ & $22 \pm 2^{*} \dagger$ & $23 \pm 3 \neq \dagger$ & $24 \pm 3 \ddagger^{*}$ & $<0.001$ \\
\hline Waist circumference, $\mathrm{cm}$ & $81 \pm 6^{*} \dagger$ & $83 \pm 8 \neq \dagger$ & $86 \pm 9 \neq$ & $<0.001$ \\
\hline Body fat, $\%$ & $16 \pm 7 \dagger$ & $17 \pm 6 \dagger$ & $20 \pm 6 \ddagger$ & $<0.001$ \\
\hline Systolic BP, mm Hg & $111 \pm 12^{*} \dagger$ & $114 \pm 12 \ddagger$ & $116 \pm 11 \ddagger$ & $<0.001$ \\
\hline Diastolic BP, mm Hg & $69 \pm 8^{*} \dagger$ & $73 \pm 8 \ddagger$ & $74 \pm 9 \ddagger$ & $<0.001$ \\
\hline Heart rate, bpm & $60 \pm 10^{*} \dagger$ & $57 \pm 11 \ddagger$ & $57 \pm 11 \ddagger$ & $<0.001$ \\
\hline Glucose, mg/dL & $93 \pm 7 \dagger$ & $93 \pm 7^{c}$ & $95 \pm 9 \ddagger$ & 0.002 \\
\hline Total cholesterol, mg/dL & $171 \pm 33^{*} \dagger$ & $182 \pm 34 \neq \dagger$ & $191 \pm 34 \ddagger$ & $<0.001$ \\
\hline $\mathrm{HDL}, \mathrm{mg} / \mathrm{dL}$ & $64 \pm 17 \dagger$ & $66 \pm 16 \dagger$ & $59 \pm 15 \ddagger$ & $<0.001$ \\
\hline $\mathrm{LDL}, \mathrm{mg} / \mathrm{dL}$ & $95 \pm 27^{*}+$ & $103 \pm 28 \ddagger$ & $116 \pm 31 \ddagger$ & $<0.001$ \\
\hline Triglycerides, mg/dL & $69 \pm 31 *+$ & $77 \pm 37 \pm \dagger$ & $86 \pm 41 \ddagger$ & $<0.001$ \\
\hline $\begin{array}{l}\text { Positive family history, } \\
\mathrm{n}(\%)\end{array}$ & $52(18)$ & $94(17)$ & $39(20)$ & 0.573 \\
\hline Max. exercise load, watt & $231 \pm 56^{*} \dagger$ & $253 \pm 61 \ddagger$ & $244 \pm 59 \ddagger$ & $<0.001$ \\
\hline Peak systolic BP, mm Hg & $178 \pm 21^{*} \dagger$ & $184 \pm 23 \ddagger$ & $184 \pm 21 \ddagger$ & $<0.001$ \\
\hline Peak diastolic BP, mm Hg & $70 \pm 8^{*} \dagger$ & $75 \pm 9 \neq \dagger$ & $77 \pm 9 \ddagger$ & $<0.001$ \\
\hline LV wall thickness, mm & $9 \pm 1 *+$ & $10 \pm 1 \ddagger$ & $10 \pm 1 \ddagger$ & $<0.001$ \\
\hline LV cavity diameter, mm & $51 \pm 4^{*} \dagger$ & $53 \pm 5 \ddagger$ & $53 \pm 4 \ddagger$ & $<0.001$ \\
\hline Ejection fraction, \% & $65 \pm 6$ & $65 \pm 6$ & $65 \pm 6$ & 0.967 \\
\hline Left atrial diameter, $\mathrm{mm}$ & $33 \pm 4^{*} \dagger$ & $35 \pm 4 \pm \dagger$ & $36 \pm 4 \ddagger$ & $<0.001$ \\
\hline Aortic root, mm & $29 \pm 3^{*} \dagger$ & $30 \pm 4 \ddagger \dagger$ & $32 \pm 4 \ddagger$ & $<0.001$ \\
\hline LV mass index, $\mathrm{g} / \mathrm{m}^{2}$ & $90 \pm 18^{*} \dagger$ & $101 \pm 23 \ddagger$ & $100 \pm 20 \ddagger$ & $<0.001$ \\
\hline E/A ratio & $2.0 \pm 0.5^{*} \dagger$ & $1.9 \pm 0.5 \ddagger \dagger$ & $1.7 \pm 0.6 \ddagger$ & $<0.001$ \\
\hline TDI e', cm/s & $14 \pm 2^{*} \dagger$ & $14 \pm 2 \ddagger \dagger$ & $13 \pm 2 \ddagger$ & $<0.001$ \\
\hline E/e' ratio & $6.6 \pm 1.3$ & $6.5 \pm 1.4$ & $6.3 \pm 1.5$ & 0.246 \\
\hline
\end{tabular}

*Young adult athletes.

tOlder adult athletes.

¥Adolescent athletes.

$\mathrm{BMI}$, body mass index; BP, blood pressure; BSA, body surface area; HDL, high-

density lipoprotein; LDL, low-density lipoprotein; LV, left ventricular; max, maximum; TDI, tissue Doppler imaging.

Adolescent athletes had lower weight, lower BSA, lower BMI and lower waist circumference as compared with other athletes (overall $\mathrm{p}$ value $<0.001$ ). Young athletes had lower BMI and waist circumference as compared with older adult athletes. The percentage of body fat was greater in older adult athletes as compared with the other groups $(\mathrm{p}<0.001)$. Systolic and diastolic blood pressure was higher and resting heart rate lower in older adults in comparison to younger groups.

A significant trend for increased total and LDL cholesterol and triglycerides was observed with ageing (overall $\mathrm{p}$ value $<0.001$ ), although the values were within the normal limits; HDL cholesterol was lower in older athletes as compared with adolescent athletes. Similarly, glucose was higher in older athletes $(p=0.002)$. The peak exercise load was greater in the young adults, while both adolescent and older athletes had relatively lower exercise performance. LV cavity, wall thickness and mass, as well as left atrial and aortic size increased significantly with increasing age $(\mathrm{p}<0.001)$, while LV ejection fraction did no differ among the groups, and E/A ratio, as expression of $\mathrm{LV}$ diastolic filling, decreased with age $(\mathrm{p}<0.001)$.

Demographic and clinical characteristics of the study population according to the type of sports are shown in table 2. There were no differences in terms of age among sport groups. Athletes practising mixed sports had the largest body weight, BSA and waist circumference compared with other groups and power athletes had the highest BMI; the highest percentage in body fat was found in skill disciplines, while endurance athletes had the highest value of HDL cholesterol. Diastolic BP did not differ among the groups, while peak systolic BP was highest in endurance athletes, who also attained the highest maximal exercise workload. LV ejection fraction did not differ among groups; cardiac dimensions presented a gradual increase of LV cavity, wall thickness, mass as well as LA and aortic root going from skill, power, mixed to endurance athletes.

\section{Cardiovascular risk factors analysis}

The distribution of $\mathrm{CV}$ risk factors in the overall population is shown in figure 1 . The most common risk factor was dyslipidemia, followed by increased waist circumference and positive family history. Specifically, dyslipidemia was detected in 337 (32\%), increased waist circumference was present in $260(25 \%)$, a positive family history of CV disease in 185 athletes (18\%). Moreover, smoking habits was declared by 88 athletes (8\%), while hypertension was found in 40 athletes $(3.8 \%)$ and hyperglycaemia in only $3(0.3 \%)$.

Presence and distribution of multiple risk factors is shown in figure 2; 418 athletes $(40 \%)$ had no CV factors, 414 had only 1 (39\%), 187 had $2(18 \%), 37$ had $3(3.5 \%)$ and $2(0.2 \%)$ had 4 $\mathrm{CV}$ risk factors.

The characteristics of the athletic population according to the number of $\mathrm{CV}$ risk factors and the gender for each group are reported in table 3 and in figure 3.

Athletes with no CV risk factors, comprising a large subset of $63 \%$ of the males and $30 \%$ of the females, were younger than the other groups $(p<0.001)$ and had a lower weight, BMI and percentage of body fat $(\mathrm{p}<0.001)$. Endurance and mixed athletes were less frequently represented in the group with multiple CV risk factors ( $\mathrm{p}=0.001$ and $\mathrm{p}=0.019$, respectively), while athletes participating in skill and power disciplines were equally distributed among different risk groups $(\mathrm{P}=0.077$ and $\mathrm{P}=0.40$, respectively).

On multivariate logistic regression analysis age, BMI and body fat were identified as independent predictors of increased $\mathrm{CV}$ risk $(\mathrm{B}=0.09 \pm 0.04, \mathrm{p}<0.001 ; \mathrm{B}=0.14 \pm 0.06, \mathrm{~B}=0.11 \pm 0.03)$, while type of sport had no significant impact (see online supplementary table 1).

\section{DISCUSSION}

Regular physical activity is an established strategy for reducing incidence and severity of adverse CV events, due to reduction in prevalence and severity of CV risk factors, including hypertension, LDL cholesterol and non-HDL cholesterol, body weight and type 2 diabetes mellitus. ${ }^{7}$ Therefore, key point of the strategy for $\mathrm{CV}$ prevention is the implementation at large of regular exercise programmes and sport participation. Intuitively, young adult competitive athletes represent the model of 'CV health', because of the assumed low prevalence of $\mathrm{CV}$ risk factors, and for their superior physical fitness.

However, scientific evidence supporting this hypothesis is scarce and, conversely, observations from selected cohorts of elite athletes have challenged this view, by reporting an unexpected large prevalence of CV risk factors. Steffes et al found that $6.8 \%(n=14 / 123)$ of high-school and college football players have multiple risk factors, consistent with diagnosis of metabolic syndrome and/or CV disease. ${ }^{2}$ A surprising high CV 
Table 2 Demographic, clinical and echocardiographic characteristics of the study population according to the type of sports participated

\begin{tabular}{|c|c|c|c|c|c|}
\hline Parameter & $\begin{array}{l}\text { Skill (s) } \\
n=227\end{array}$ & $\begin{array}{l}\text { Power (p) } \\
n=193\end{array}$ & $\begin{array}{l}\text { Mixed (m) } \\
n=345\end{array}$ & Endurance (e) $n=293$ & $P$ values \\
\hline Age, years & $24 \pm 6$ & $24 \pm 4$ & $24 \pm 6$ & $24 \pm 5$ & 0.908 \\
\hline Height, $\mathrm{cm}$ & $172 \pm 10^{*} \dagger$ & $174 \pm 10^{*} \dagger$ & $185 \pm 11 \neq \S \dagger$ & $178 \pm 10^{*} \ddagger \S$ & $<0.001$ \\
\hline Weight, kg & $68 \pm 14 \S^{*} \dagger$ & $73 \pm 18 \ddagger^{*}$ & $78 \pm 12 \neq \S \dagger$ & $71 \pm 13 \ddagger^{*}$ & $<0.001$ \\
\hline $\mathrm{BSA}, \mathrm{m}^{2}$ & $1.80 \pm 0.22 \S^{*} \dagger$ & $1.86 \pm 0.25 \ddagger^{*}$ & $2.02 \pm 0.22 \neq \S \dagger$ & $1.89 \pm 0.22 \ddagger^{*}$ & $<0.001$ \\
\hline BMI, kg/m² & $23 \pm 3 \S \dagger$ & $24 \pm 4 \ddagger^{*} \dagger$ & $23 \pm 2 \S \dagger$ & $22 \pm 2 \S^{*}$ & $<0.001$ \\
\hline Waist circumference, $\mathrm{cm}$ & $82 \pm 9^{*}$ & $82 \pm 10^{*}$ & $85 \pm 6 \ddagger \S \dagger$ & $82 \pm 7^{*}$ & $<0.001$ \\
\hline Body fat, $\%$ & $20 \pm 7 \S \dagger$ & $16 \pm 7 \ddagger$ & $18 \pm 6 t$ & $15 \pm 5 \ddagger^{*}$ & $<0.001$ \\
\hline Systolic BP, mm Hg & $111 \pm 12 \dagger$ & $112 \pm 14 \dagger$ & $113 \pm 11 \dagger$ & $116 \pm 11 \ddagger \S^{*}$ & $<0.001$ \\
\hline Diastolic BP, mm Hg & $71 \pm 9+$ & $71 \pm 9+$ & $72 \pm 8$ & $73 \pm 8 \neq \S$ & 0.008 \\
\hline Heart rate, bpm & $61 \pm 11^{*}$ & $59 \pm 11 \dagger$ & $58 \pm 10 \neq \dagger$ & $54 \pm 10 \neq \S^{*}$ & $<0.001$ \\
\hline Glucose, mg/dL & $95 \pm 7 \dagger$ & $93 \pm 7$ & $93 \pm 8$ & $93 \pm 8 \ddagger$ & 0.034 \\
\hline Total cholesterol, mg/dL & $186 \pm 39$ & $178 \pm 32$ & $180 \pm 32$ & $180 \pm 34$ & 0.105 \\
\hline $\mathrm{HDL}, \mathrm{mg} / \mathrm{dL}$ & $63 \pm 16 t$ & $63 \pm 16 t$ & $62 \pm 14 \dagger$ & $68 \pm 19 \neq \S^{*}$ & $<0.001$ \\
\hline $\mathrm{LDL}, \mathrm{mg} / \mathrm{dL}$ & $109 \pm 32 \S \dagger$ & $101 \pm 29 \ddagger$ & $102 \pm 29$ & $101 \pm 27 \ddagger$ & 0.005 \\
\hline Triglycerides, mg/dL & $79 \pm 32$ & $77 \pm 37$ & $78 \pm 37$ & $72 \pm 38$ & 0.146 \\
\hline Positive family $\mathrm{Hx}, \mathrm{n}(\%)$ & $48(21)$ & $31(16)$ & $61(18)$ & $45(15)$ & 0.348 \\
\hline Max. exercise load, watts & $209 \pm 52 \S^{*} \dagger$ & $228 \pm 52 \ddagger^{*} \dagger$ & $248 \pm 44 \neq \S \dagger$ & $282 \pm 66 \S \ddagger^{*}$ & $<0.001$ \\
\hline Peak systolic BP, mm Hg & $174 \pm 20^{*} \dagger$ & $177 \pm 22^{*} \dagger$ & $184 \pm 21 \ddagger \S$ & $191 \pm 22 \ddagger \S$ & $<0.001$ \\
\hline Peak diastolic BP, mm Hg & $73 \pm 9$ & $75 \pm 9$ & $75 \pm 9$ & $73 \pm 9$ & 0.050 \\
\hline LV wall thickness, mm & $9 \pm 1 \S^{*} \dagger$ & $9 \pm 1 \dagger \ddagger$ & $10 \pm 1 \ddagger \dagger$ & $10 \pm 1 \neq \S^{*}$ & $<0.001$ \\
\hline LV cavity diameter, $\mathrm{mm}$ & $49 \pm 4 \S \dagger$ & $51 \pm 4 \ddagger \dagger$ & $53 \pm 4 \ddagger \S \dagger$ & $55 \pm 5 \neq \S^{*}$ & $<0.001$ \\
\hline Ejection fraction, \% & $65 \pm 6$ & $65 \pm 6$ & $64 \pm 6$ & $65 \pm 6$ & 0.579 \\
\hline Left atrial diameter, mm & $33 \pm 4 \S^{*} \dagger$ & $34 \pm 4 \ddagger \dagger$ & $35 \pm 4 \ddagger \dagger$ & $37 \pm 4 \mp \S^{*}$ & $<0.001$ \\
\hline Aortic root, mm & $29 \pm 4^{*} \dagger$ & $30 \pm 4^{*} \dagger$ & $31 \pm 3 \neq \S$ & $31 \pm 4 \ddagger \S$ & $<0.001$ \\
\hline LV mass index, $\mathrm{g} / \mathrm{m}^{2}$ & $84 \pm 15 \S^{*} \dagger$ & $93 \pm 18 \neq \dagger$ & $94 \pm 17 \ddagger \dagger$ & $115 \pm 23 \ddagger \S^{*}$ & $<0.001$ \\
\hline E/A ratio & $1.9 \pm 0.5$ & $1.9 \pm 0.6$ & $1.9 \pm 0.5 \dagger$ & $2.0 \pm 0.5^{*}$ & 0.014 \\
\hline TDI e', cm/s & $14 \pm 2$ & $14 \pm 2$ & $14 \pm 2$ & $14 \pm 2$ & 0.104 \\
\hline E/e' ratio & $6.5 \pm 1.4$ & $6.7 \pm 1.6^{*}$ & $6.3 \pm 1.3 \S$ & $6.5 \pm 1.3$ & 0.012 \\
\hline
\end{tabular}

${ }^{*}$ Mixed.

tEndurance.

$\ddagger$ §kill.

§Power.

BMI, body mass index; BP, blood pressure; BSA, body surface area; HDL, high-density lipoprotein; LDL, low-density lipoprotein; LV, left ventricle; max, maximum; TDI, tissue Doppler imaging.

risk profile was demonstrated in active professional football players, ${ }^{34}$ in retired middle-aged professional athletes ${ }^{5}$ and in young college football players. ${ }^{7-9}$ In these series, the prevalence of $\mathrm{CV}$ risks in active professional athletes was similar to the age-matched sedentary US population. ${ }^{2}$ Furthermore, former
National Football League linemen have a 52\% greater risk of death from CV disease compared with the general population, and almost $60 \%$ of retired linemen have metabolic syndrome. ${ }^{4}$

Unfortunately, due to lack of reliable data from large cohorts of young and adult athletes, including women, their CV risk profile

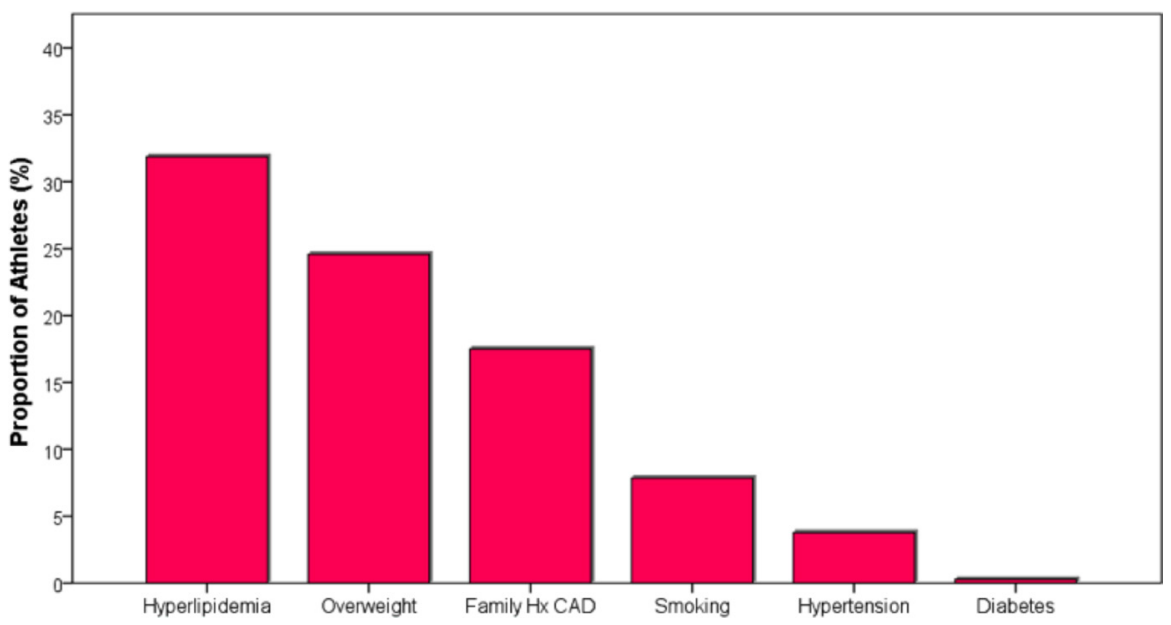

Figure 1 Proportion of Olympic athletes with cardiovascular risk factors. CAD, coronary artery disease. 


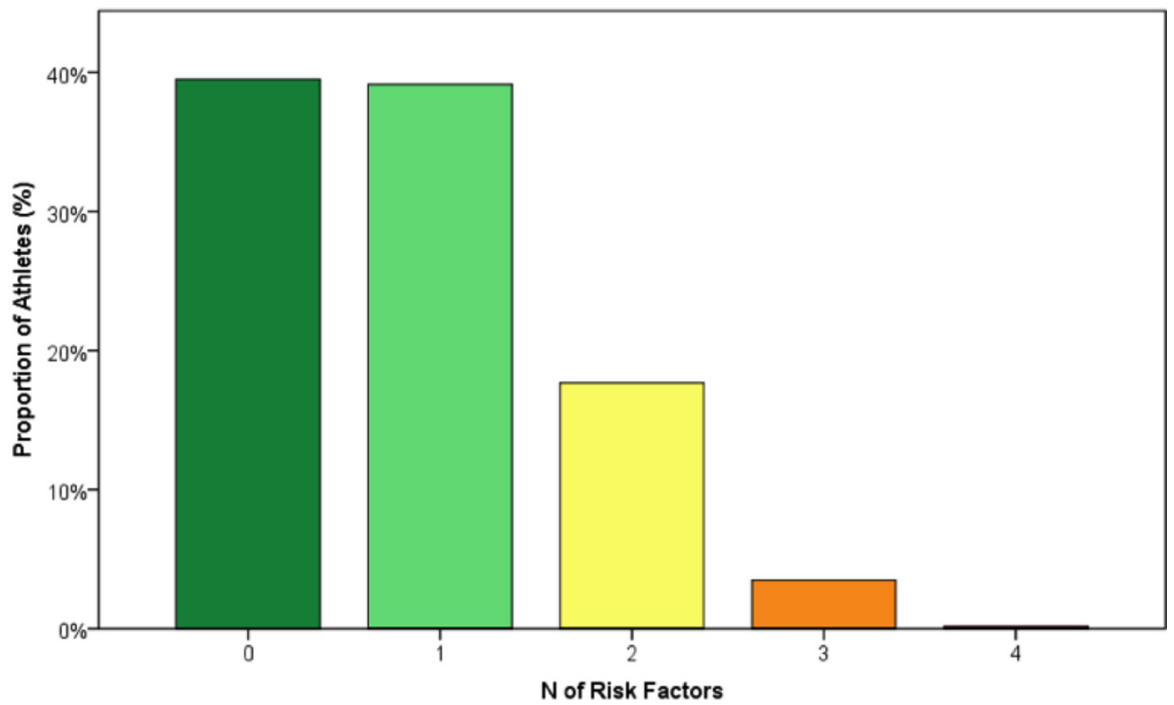

Figure 2 Number of cardiovascular risk factors found in the population of Olympic athletes.

is not adequately known, and these categories continue to be under-represented in clinical studies and trials. ${ }^{10-28}$ Therefore, taking advantage of the Olympic screening programme implemented in our Institute, ${ }^{12}$ in this study we assessed the prevalence and distribution of CV risk factors in a large population of young adults regularly engaged in intensive exercise programmes, encompassing individuals of both gender, of varied social and cultural levels. Indeed, our cohort is representative of the Italian population in terms of gender distribution, geographic origin, socioeconomic and educational level and might be seen as a reliable mirror of the entire Italian population of comparable age.

Among the CV risk factors, dyslipidemia and increased waist circumference were the most frequently observed, followed by family history of coronary artery disease, smoking, hypertension and far less, by diabetes.

We confirmed that age, as expected, has a relevant impact on CV risk profile, with athletes over 30 years showing greater waist circumference, weight, systolic and diastolic blood pressure values and relatively higher levels of glycaemia, triglycerides, total and LDL cholesterol, and lower HDL cholesterol as compared with younger groups. These findings demonstrate that

Table 3 Characteristics of the athletic population according to the number of cardiovascular risk factors

\begin{tabular}{lllll}
\hline & $\begin{array}{l}\text { No risk } \\
\text { factors } \\
\mathbf{n}=418\end{array}$ & $\begin{array}{l}1-2 \text { risk } \\
\text { factors } \\
\mathbf{n}=601\end{array}$ & $\begin{array}{l}3-4 \text { risk } \\
\text { factors } \\
\mathbf{n}=39\end{array}$ & P values \\
\hline Age, years & $23 \pm 5$ & $25 \pm 6$ & $27 \pm 6^{*}$ & $<0.001$ \\
\hline Gender, males & $297(71 \%)$ & $337(56 \%)$ & $22(56 \%)$ & $<0.001$ \\
\hline Height, $\mathrm{cm}$ & $179 \pm 11$ & $178 \pm 12$ & $182 \pm 10$ & 0.124 \\
\hline Weight, $\mathrm{kg}$ & $71 \pm 13$ & $74 \pm 15$ & $86 \pm 19 \dagger$ & $<0.001$ \\
\hline BSA, ${ }^{2}$ & $1.89 \pm 0.23$ & $1.91 \pm 0.24$ & $2.07 \pm 0.25^{*} \dagger$ & $<0.001$ \\
\hline BMl & $22 \pm 2$ & $23 \pm 3$ & $26 \pm 5^{*} \dagger$ & $<0.001$ \\
Body fat, \% & $15 \pm 5$ & $19 \pm 7$ & $25 \pm 8^{*} \dagger$ & $<0.001$ \\
\hline Heart rate, bpm & $58 \pm 11$ & $57 \pm 11$ & $61 \pm 13$ & 0.143 \\
\hline Skill disciplines & $76(33 \%)$ & $140(62 \%)$ & $11(5 \%)$ & 0.077 \\
\hline Power disciplines & $84(44 \%)$ & $103(53 \%)$ & $6(3 \%)$ & 0.401 \\
\hline Mixed disciplines & $117(34 \%)$ & $211(61 \%)$ & $17(5 \%)$ & 0.019 \\
\hline Endurance disciplines & $141(48 \%)$ & $147(50 \%)$ & $5(2 \%)$ & 0.001 \\
\hline${ }^{*} \mathrm{p}<0.05$ vs no risk factors group. & & & \\
tp<0.005 vs 1-2 risk factors group. & & & \\
\hline
\end{tabular}

ageing, even in the period of youth, represents per se a major determinant for worsening the CV risk profile. Therefore, our findings suggest that sport participation does not guarantee, per se, to eliminate being overweight and does not eliminate the trend towards increased values in LDL, triglycerides and glucose. This observation highlights the concept that even young athletes are not immune from unfavourable risk profile and confirms the importance for starting in the very early period of the individual's life the appropriate strategies to manage CV risk factors.

Our study showed that type of sport has a relevant impact on $\mathrm{CV}$ risk profile. As expected, endurance athletes exhibited the best risk profile, with the highest values of HDL cholesterol, the lowest levels of glycaemia, total and LDL cholesterol, triglycerides, waist circumference and percentage of body fat. Consistently, the best risk profile was associated with the highest level of physical performance, as testified by the highest peak workloads attained at exercise testing. These findings are in agreement with several previous observations showing the beneficial effects of aerobic exercise on

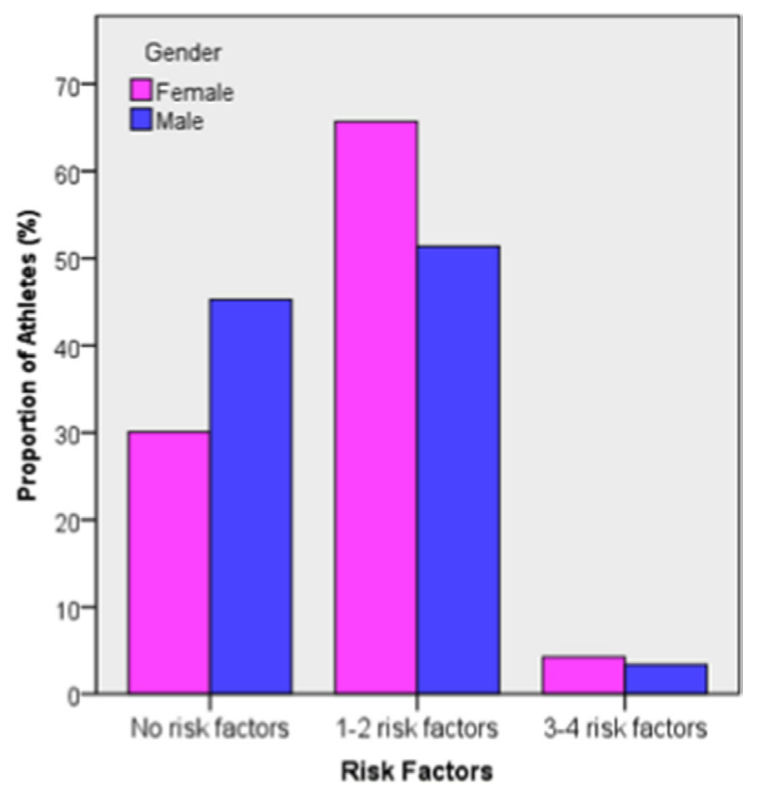

Figure 3 Number of cardiovascular risk factors found in the population of Olympic athletes according to gender. 
$\mathrm{CV}$ risk factors and further support the view that aerobic power represents a parameter of CV health. ${ }^{129}$

In our athlete's population, dyslipidemia and increased waist circumference are by far the most common risk factors, extending to the athlete's population the currently observed pandemic of these anomalies in the general population. It is worthy to notice that sport participated had no or only mild impact on the prevalence of these abnormalities, with the remarkable exception of the endurance (aerobic) sport disciplines.

Of notice, a small subset of our athletes (4\% of females and 3\% of males), showed a high-risk profile, defined by the association of multiple (ie, $\geq 3$ ) risks factors. They were more commonly engaged in mixed and skill disciplines, were relatively older and had higher body size and fat percentage compared with the athletes engaged in the other sport. The most common risk factors in this subset were also hyperlipidemia (90\%), increased waist circumference (84\%), family history (62\%), smoking habit (44\%) and hypertension (25\%). Therefore, the high-risk profile appeared to be largely related to modifiable risk factors with the potential to reduce the CV risk with appropriate dietary consultation and stop smoking.

It is worthy of notice the large subset of athlete's population presenting none of CV risk factors. We saw these athletes with particular interest because they epitomised the model of the optimal risk profile and represented the desirable goal for $\mathrm{CV}$ risk management. The observed level of CV risk factors in this selected cohort of athletes should be ideally considered the reference value and the desirable target when managing abnormal risk profile in young and adult individuals, although the intensity and training volume desirable to change the CV risk profile is currently debated.

Specifically, comparing the findings of our athletes with no CV risk factors versus the advised reference values suggested by the current recommendations, ${ }^{1}$ we noticed that our athletes had more stringent mean values for LDL, total cholesterol, triglycerides and systolic/diastolic blood pressure: namely, triglycerides by $-15 \%$, (ie, $<127$ vs $<150 \mathrm{mg} / \mathrm{dL}$,), HDL cholesterol by $+122 \%$ in men (ie, 89 vs $>40 \mathrm{mg} / \mathrm{dL}$ ) and $+106 \%$ in women (ie, 93 vs $>45 \mathrm{mg} /$ $\mathrm{dL}$ ). Conversely, the values of LDL cholesterol (111 vs $115 \mathrm{mg} /$ $\mathrm{dL}$, respectively) and waist circumference (91 vs $94 \mathrm{~cm}$ in men and $<79$ vs $<80 \mathrm{~cm}$ in women, respectively) were not dissimilar from what suggested by recommendations.

\section{LIMITATIONS}

This is the first study assessing the prevalence and distribution of $\mathrm{CV}$ risk factors in Olympic athletes. The main limitation of the present study is represented by its cross-sectional design with the lack of outcome data. Future studies should be planned to explore the prognostic impact of assessing and managing CV risk factors in a population of otherwise healthy athletes.

A control group of young sedentary subjects comparable to our cohort of elite athletes is not available. Unfortunately, also the available literature does not report data on a similar population of age-matched and sex-matched young sedentary individuals.

Finally, the use of non-steroidal anti-inflammatory drugs and supplements and high salt intake are largely reported by athletes and their impact on some of the most relevant factors has not been adequately investigated. Further studies are needed to evaluate their prognostic impact on CV health.

\section{CONCLUSIONS}

Our study shows that elite athletes are not immune from most of $\mathrm{CV}$ risk factors, with dyslipidemia and increased waist circumference affecting a substantial proportion of individuals (32\% and 25\%, respectively). A substantial proportion of elite athletes $(40 \%)$ are free from all the recognised risk factors. However, a small minority presents a high CV risk profile, largely expression of lifestyle and related to modifiable CV risk factors.

Contributors The authors declared no conflicts of interest.

Funding The authors have not declared a specific grant for this research from any funding agency in the public, commercial or not-for-profit sectors.

Competing interests None declared.

Patient consent Obtained.

Ethics approval Local Ethics Committee of the Institute of Sports Medicine.

Provenance and peer review Not commissioned; externally peer reviewed.

\section{REFERENCES}

1 Piepoli MF, Hoes AW, Agewall S, et al. Authors/Task Force Members. 2016 European guidelines on cardiovascular disease prevention in clinical practice: The sixth joint task force of the european society of cardiology and other societies on cardiovascular disease prevention in clinical practice (constituted by representatives of 10 societies and by invited experts) developed with the special contribution of the European Association for Cardiovascular Prevention \& Rehabilitation (EACPR). Eur J Prev Cardiol 2016.

2 Mensink GB, Loose N, Oomen CM. Physical activity and its association with other lifestyle factors. Eur J Epidemiol 1997;13:771-8.

3 Sibley C, Blumenthal RS, Merz CN, et al. Limitations of current cardiovascular disease risk assessment strategies in women. J Womens Health 2006;15:54-6.

4 Steffes GD, Megura AE, Adams J, et al. Prevalence of metabolic syndrome risk factors in high school and NCAA division I football players. I Strength Cond Res 2013;27:1749-57.

5 Tucker AM, Vogel RA, Lincoln AE, et al. Prevalence of cardiovascular disease risk factors among National Football League players. JAMA 2009;301:2111-9.

6 Miller MA, Croft LB, Belanger AR, et al. Prevalence of metabolic syndrome in retired National Football League players. Am J Cardio/ 2008;101:1281-4.

7 Borchers JR, Clem KL, Habash DL, et al. Metabolic syndrome and insulin resistance in Division 1 collegiate football players. Med Sci Sports Exerc 2009:41:2105-10.

8 Buell JL, Calland D, Hanks F, et al. Presence of metabolic syndrome in football linemen. J Ath/ Train 2008;43:608-16.

9 Haskins S, Bernhardt DT, Koscik RL. Screening for insulin resistance and cardiovascular risk in collegiate football linemen. Clin J Sport Med 2011;21:233-6.

10 Malina RM, Morano PJ, Barron M, et al. Overweight and obesity among youth participants in American football. J Pediatr 2007;151:378-82.

11 Wilkerson GB, Bullard JT, Bartal DW. Identification of cardiometabolic risk among collegiate football players. J Athl Train 2010;45:67-74.

12 Pelliccia A, Adami PE, Quattrini F, et al. Are Olympic athletes free from cardiovascular diseases? Systematic investigation in 2352 participants from Athens 2004 to Sochi 2014. Br J Sports Med 2017:51:238-43.

13 Caselli S, Di Paolo FM, Pisicchio C, et al. Patterns of left ventricular diastolic function in Olympic athletes. J Am Soc Echocardiogr 2015;28:236-44.

14 D'Ascenzi F, Pisicchio C, Caselli S, et al. RV Remodeling in Olympic Athletes. JACC Cardiovasc Imaging 2017;10:385-93.

15 . http://www.wada-ama.org/en/content/what-is-prohibited

16 Mosteller RD. Simplified calculation of body-surface area. N Eng/ J Med 1987;317:1098.

17 Drezner JA, Sharma S, Baggish A, et al. International criteria for electrocardiographic interpretation in athletes: Consensus statement. Br J Sports Med 2017;51:704-31.

18 Caselli S, Vaquer Segui A, Quattrini F, et al. Upper normal values of blood pressure response to exercise in Olympic athletes. Am Heart J 2016;177:120-8.

19 Lang RM, Badano LP, Mor-Avi V, et al. Recommendations for cardiac chamber quantification by echocardiography in adults: an update from the American Society of Echocardiography and the European Association of Cardiovascular Imaging. J Am SoC Echocardiogr 2015;28:1-39.

20 Pelliccia A, Caselli S, Sharma S, et al. European Association of Preventive Cardiology (EAPC) and European Association of Cardiovascular Imaging (EACVI) joint position statement: recommendations for the indication and interpretation of cardiovascular imaging in the evaluation of the athlete's heart. Eur Heart J 2018;39:1949-69.

21 Devereux RB. Detection of left ventricular hypertrophy by M-mode echocardiography. Anatomic validation, standardization, and comparison to other methods. Hypertension 1987;9(2 Pt 2):II19-26.

22 Maragiannis D, Nagueh SF. Echocardiographic evaluation of left ventricular diastolic function: an update. Curr Cardiol Rep 2015;17:3.

23 American Diabetes Association. Diagnosis and classification of diabetes mellitus. Diabetes Care 2014;37 Suppl 1(Suppl 1):S81-S90. 
24 Stone NJ, Robinson JG, Lichtenstein AH, et al. 2013 ACC/AHA Guideline on the treatment of blood cholesterol to reduce atherosclerotic cardiovascular risk in adults. J Am Coll Cardiol 2014;63:2889-934.

25 Berry JD, Dyer A, Cai X, et al. Lifetime risks of cardiovascular disease. N Engl J Med Overseas Ed 2012;366:321-9.

26 Grundy SM, Barlow CE, Farrell SW, et al. Cardiorespiratory fitness and metabolic risk. Am J Cardiol 2012;109:988-93.
27 Di Castelnuovo A, Costanzo S, Persichillo M, et al. MOLI-SANI Project Investigators. Distribution of short and lifetime risks for cardiovascular disease in Italians. Eur J Prev Cardiol 2012;19:723-30.

28 Berry JD, Lloyd-Jones DM, Garside DB, et al. Framingham risk score and prediction of coronary heart disease death in young men. Am Heart J 2007;154:80-6.

29 Myers J, Prakash M, Froelicher V, et al. Exercise capacity and mortality among men referred for exercise testing. N Eng/ J Med 2002;346:793-801. 